Research article

Open Access

\title{
Dissection of a locus on mouse chromosome 5 reveals arthritis promoting and inhibitory genes
}

\author{
Therese Lindvall1 ${ }^{\text {, Jenny Karlsson }}{ }^{1,3}$, Rikard Holmdahl ${ }^{1}$ and Åsa Andersson ${ }^{2}$
}

\begin{abstract}
1Department of Experimental Medical Science, Unit for Medical Inflammation Research, BMC 111, Lund University, S-221 84 Lund, Sweden 2Department of Pharmacology and Pharmacotherapy, Faculty of Pharmaceutical Sciences, Copenhagen University, Universitetsparken 2, DK-2100 Copenhagen $\varnothing$, Denmark

${ }^{3}$ Current address: Pathology and Laboratory Medicine, University of California Los Angeles, 675 S. Charles E. Young Drive, Los Angeles, CA 90095, USA
\end{abstract}

Corresponding author: Therese Lindvall, therese.lindvall@med.lu.se

Received: 18 Jul 2008 Revisions requested: 9 Aug 2008 Revisions received: 2 Dec 2008 Accepted: 20 Jan 2009 Published: 20 Jan 2009

Arthritis Research \& Therapy 2009, 11:R10 (doi:10.1186/ar2597)

This article is online at: http://arthritis-research.com/content/11/1/R10

(C) 2009 Lindvall et al:; licensee BioMed Central Ltd.

This is an open access article distributed under the terms of the Creative Commons Attribution License (http://creativecommons.org/licenses/by/2.0), which permits unrestricted use, distribution, and reproduction in any medium, provided the original work is properly cited.

\begin{abstract}
Introduction In a cross between two mouse strains, the susceptible B10.RIII (H-2r) and resistant RIIIS/J (H-2r) strains, a locus on mouse chromosome 5 (Eae39) was previously shown to control experimental autoimmune encephalomyelitis (EAE). Recently, quantitative trait loci (QTL), linked to disease in different experimental arthritis models, were mapped to this region. The aim of the present study was to investigate whether genes within Eae39, in addition to $E A E$, control development of collagen-induced arthritis (CIA).

Methods ClA, induced by immunisation with bovine type II collagen, was studied in Eae39 congenic and sub-interval congenic mice. Antibody titres were investigated with ELISA. Gene-typing was performed by micro-satellite mapping and statistics was calculated by standard methods.
\end{abstract}

Results Experiments of CIA in Eae39 congenic- and subinterval congenic mice, carrying RIIIS/J genes on the B10.RIII genetic background, revealed three loci within Eae39 that control disease and anti-collagen antibody titres. Two of the loci promoted disease and the third locus was protected against CIA development. By further breeding of mice with small congenic fragments, we identified a 3.2 mega base pair (Mbp) interval that regulates disease.

Conclusions Disease-promoting and disease-protecting genes within the Eae39 locus on mouse chromosome 5 control susceptibility to $\mathrm{CIA}$. A disease-protecting locus in the telomeric part of Eae39 results in lower anti-collagen antibody responses. The study shows the importance of breeding sub-congenic mouse strains to reveal genetic effects on complex diseases.

\section{Introduction}

Rheumatoid arthritis (RA) and multiple sclerosis (MS) are complex inflammatory autoimmune disorders in which genetic and environmental factors contribute to disease development [1]. $\mathrm{RA}$ is characterised by peripheral joint inflammation, cartilage and bone destruction and, subsequently, joint deformation. In MS, the myelin and axons are affected by inflammation within the CNS often leading to severe neurological dysfunction. The disease-causing mechanisms remain unknown, although it is known that the aetiology is dependent on multiple genetic and environmental factors. To date, only a few genes have been associated with susceptibility to RA [2-4] and MS [5,6].

The most commonly used animal model for RA is collageninduced arthritis (CIA) [7]. The B10.RIII (H-2r) mouse strain develops poly-arthritis after immunisation with bovine type II collagen, whereas the RIIIS/J mouse strain, having the same major histocompatibility complex (MHC) haplotype $\left(\mathrm{H}-2^{r}\right)$, is resistant to poly-arthritis development. Induction of $\mathrm{CIA}$ is dependent on genes within the $\mathrm{MHC}$, but as previously shown in crosses between B10.RIII and RIIIS/J mice, non-MHC

AUC: area under curve; BSA: bovine serum albumin; CIA: collagen-induced arthritis; CNS: central nervous system; EAE: experimental autoimmune encephalomyelitis; ELISA: enzyme-linked immunosorbent assay; FP: front primer; IFA: incomplete Freund's adjuvant; Ig: immunoglobulin; Mbp: mega base pairs; MHC: major histocompatibility complex; MS: multiple sclerosis; PBS: phosphate-buffered saline; PCR: polymerase chain reaction; QTL: quantitative trait locus; RA: rheumatoid arthritis; RP: reverse primer. 
genes also play an important role in susceptibility to disease [8-10].

Experimental autoimmune encephalomyelitis (EAE) is an inflammatory demyelinating disease of the central nervous system (CNS), widely used as an animal model for MS. The B10.RIII strain is susceptible to EAE induced by the myelin basic protein (MBP) peptide 89-101 [11]. From studies of crosses between B10.RIII and RIIIS/J (resistant to EAE development), a number of non-MHC quantitative trait loci (QTLs), linked to EAE susceptibility, have been reported [12-14]. In one study, the Eae39 locus on mouse chromosome 5 was linked to acute EAE [13]. The inheritance pattern showed that RIIIS/J genes were dominantly protective. The Eae39 locus is the only QTL linked to EAE on mouse chromosome 5, but six QTLs linked to disease in arthritis models have been identified on this chromosome: Cia13, Cia14 and Cia27 for CIA [15,16], Pgia16 for proteoglycan-induced arthritis [17], and Bbaa3 and Bbaa2 for Borrelia burgdorferi-associated arthritis [18].

The Eae39 locus was identified as a genetic region of about 30 mega base pairs (Mbp). In order to further investigate the genetic control of disease in the B10.RIII/RIIIS/J model, we have studied CIA in Eae39 and Eae39 sub-interval congenic mice. We observed three different inheritance patterns associated with arthritis development, which argues that there are at least three genes in Eae39 that are important for the development of inflammatory disease. Two of the loci, located within a distance of a few Mbp, contain genes that, depending on the allele, either protect from or promote disease. This suggests a balancing effect by closely located genes on disease susceptibility that is revealed when QTLs are split into smaller fragments.

\section{Materials and methods Animals}

C57BI/10.RIII (B10.RIII) were originally provided by J. Klein (Tübingen, Germany), and kept in the breeding colony at the Department of Medical Inflammation Research, Lund University. RIIIS/J animals were purchased from The Jackson Laboratory (Bar Harbor, ME). The Eae39 congenic mice (C1, Figure 1) were produced by marker selected backcrossing of the RIIIS/J (donor) mice to the B10.RIII (recipient) strain. All experiments were approved by the local ethical authorities in Malmö-Lund, Sweden (permit numbers: M70-04, M75-04, M107-07 and M109-07).

\section{Induction and evaluation of collagen-induced arthritis}

Bovine type II collagen was prepared from calf nasal cartilage by pepsin digestion and was purified as previously described [19]. CIA was induced by intra-dermal immunisation at the base of the mouse's tail with $100 \mu \mathrm{g}$ bovine Cll emulsified in incomplete Freund's adjuvant (IFA) (Difco, Detroit, MI, USA). The mice were boosted 35 days later with $50 \mu \mathrm{g}$ bovine Cll

\section{Figure 1}

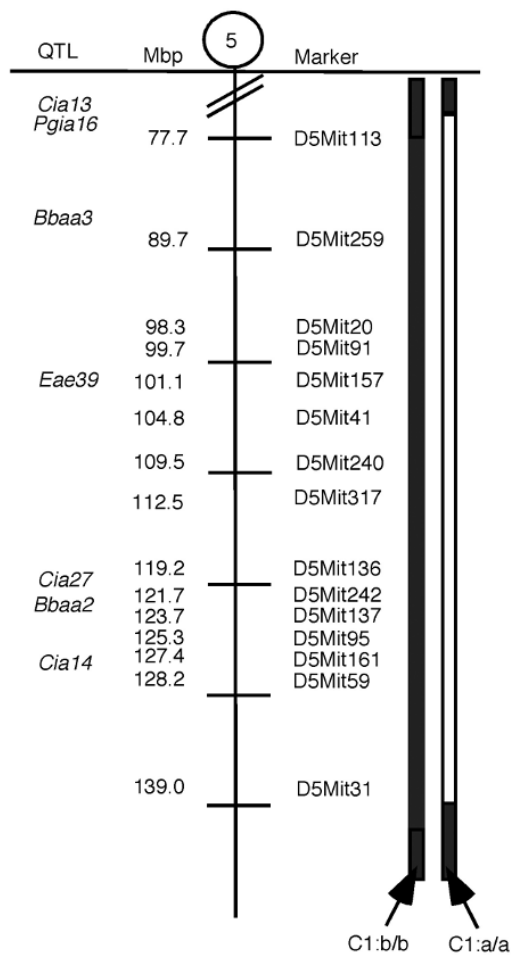

The Eae39 locus on mouse chromosome 5 . The $\mathrm{C} 1$ congenic fragment is derived from RIIIS/J and bred on to the B10.RIII background by marker selected back-crossing. Black $=$ two B10.RIII alleles; white $=$ two RIIIS/J alleles. Mbp = mega base pairs (positions according to Ensembl release 49).

emulsified in IFA. The mice, ranging in age between 10 and 24 weeks, were all immunised the same day. Clinical disease was monitored once or twice a week according to a scoring system based on the number of inflamed joints. Each inflamed toe or knuckle was given a score of one and an inflamed wrist or ankle was given five points. Each mouse could in total get 15 points per limb and a maximum score of 60 . The area under the curve (AUC) was calculated as the sum of scores for each individual mouse during a defined test period. The mean maximum score, representing disease severity, was calculated as the mean of the maximum score of all sick mice in the respective groups.

\section{Antibody measurement}

Blood was collected on day 14, 21 or day 54 after immunisation. Sera were prepared and stored at $-20^{\circ} \mathrm{C}$ until assayed. ELISA was used to determine levels of antibodies against collagen type II. Plates (Nunc maxisorp, Roskilde, Denmark) were coated with bovine Cll $(10 \mu \mathrm{g} / \mathrm{ml})$ in PBS $(\mathrm{pH} 9)$ and blocked with $1 \%$ BSA. Immunoglobulin (Ig) M, IgG1, IgG2c, IgG3 and total Ig levels were measured using biotinylated secondary antibodies: goat anti-mouse $\operatorname{lgM}$ (No. 1020-08); IgG1 (No.1070-08); IgG2c (No. 1079-04); IgG3 (No. 1100-08); 
and total Ig (No. 1010-08) (Southern Biotechnologies Associates, Birmingham, AL, USA). Binding of biotinylated antibodies was revealed by Extravidin Peroxidase (No. E-2886) (Sigma-Aldrich, St Louis, MO, USA). Plates were developed with ABTS: 2,2'-Azino-di-[3-ethylbenzthiazoline sulfonate (6)] diammonium salt (Roche, Mannheim, Germany). Pooled sera were used as a standard and the antibody levels were measured as arbitrary concentrations.

\section{Genotyping and linkage analysis}

Genomic DNA was isolated from toe or tail biopsies. The biopsies were dissolved in $500 \mu \mathrm{l}$ of $50 \mathrm{mM}$ sodium hydroxide for one to two hours at $95^{\circ} \mathrm{C}$, and subsequently neutralised with $100 \mu 1 \mathrm{mM}$ Tris- $\mathrm{HCl}(\mathrm{pH} 8)$. To perform a standard $10 \mu \mathrm{l}$ PCR, $1 \mu \mathrm{l}$ of the solution was used. The PCR products were analysed on a MegaBACE DNA analysis system 1000 (Amersham Pharmacia Biotech, Little Chalfont, UK), according to the manufacturer's protocol. Fifteen informative fluorescencelabelled micro-satellite markers (Interactiva Biotechnologie, Ulm, Germany and MWG Biotech, Ebersberg, Germany) were used to genotype the Eae39 congenic fragment. Linkage analysis and permutation tests were conducted as previously described [13]. Sub-congenic mice were genotyped with additional micro-satellite markers, where some markers are made in-house: D5acacbhm4 (114.42 Mbp, forward primer (FP) 5'-CCCTGTAGAAGACTGGGAATTG-3, reverse primer (RP) 5'-TCCAGGACAGTCAGGGCTAC-3'), D5taokhm12 (117.53 Mbp, FP: 5'-TCAGGGCTCCATGCACTT-3', RP: 5'CACAAGTGGCTCTCAGTGCT-3), D5sdshm18 (120.74 Mbp, FP: 5'-GGGGAACACAAGGAGTTTGA-3', RP: 5'ATTCAAGGGCATGTGTGTGA-3').

\section{Results \\ Eae39 controls collagen-induced arthritis}

The Eae39 locus on mouse chromosome 5 (Figure 1) was previously described in a genetic linkage analysis based on a backcross between the RIIIS/J and B10.RIII strains [13]. The confidence interval for Eae39 extended from the micro-satellite marker D5Mit259 (90 Mbp) to D5Mit136 (119 Mbp). This locus was shown to control incidence of acute EAE in male mice, with a dominant effect of RIIIS/J alleles on protection from disease development.

To further investigate the Eae39 locus, a $65 \mathrm{Mbp}$ RIIIS/J fragment was bred into the B10.RIII genome to establish a BR. Eae39RIIIS/J Congenic strain (Figure 1). This region contains a number of QTLs linked to the development of disease in experimental models for arthritis, and we wanted to investigate whether Eae39 controls the susceptibility to CIA in the B10.RIII and RIIIS/J strain combination. Thus, Eae39 congenic mice were immunised with bovine collagen type II in IFA. As shown in Figure 2 and Tables 1 and 2, genes within Eae39 control CIA. Figure 2 shows the development of disease in mice with the congenic Eae39 fragment shown in Figure 1. Mice with the $\mathrm{C} 1$ congenic fragment had higher incidence of
Figure 2

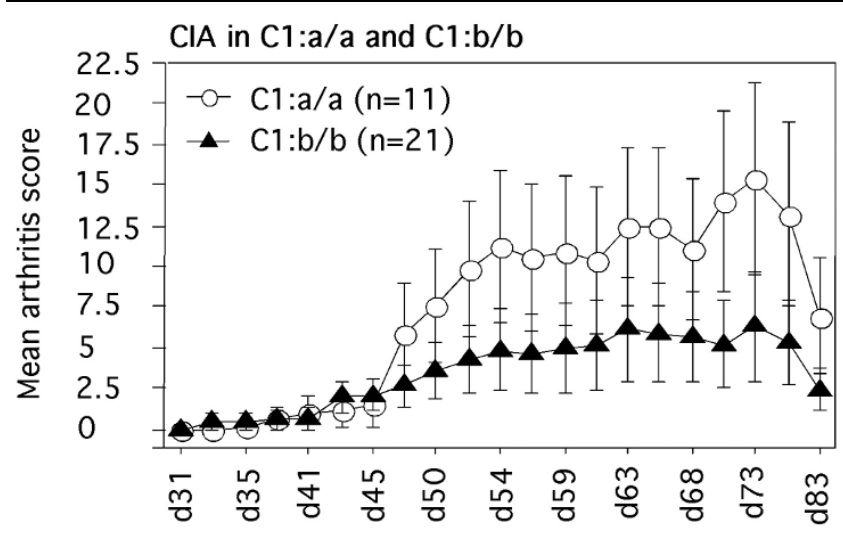

Collagen-induced arthritis (CIA) development in mice with the $\mathrm{C} 1$ congenic fragment. a/a (area under the curve (AUC) $(d 50-73)=125 \pm 50$, incidence $=64 \%), \mathrm{b} / \mathrm{b}(\mathrm{AUC}(\mathrm{d} 50-73)=57 \pm 29$, incidence $=24 \%)$, (AUC (d50-73) $p=0.0379$, Mann-Whitney $U$ test, incidence $p=$ 0.0271 , Chi squared test).

disease (64\%) and higher accumulated arthritis score (AUC $(\mathrm{d} 50-73)=125 \pm 50)$ compared with the non-congenic littermates (incidence of disease 24\%, AUC (d50-73) = $57 \pm 29$ ). (Incidence, $p=0.0271$, Chi squared test; AUC (d50-73), $p=$ 0.0379, Mann-Whitney U test).

Next, we intercrossed $\mathrm{C} 1$ heterozygous mice in order to get offspring with overlapping congenic fragments (Figure 3 ) to pinpoint smaller intervals within Eae39 linked to the disease phenotype. The mice were investigated for development of $\mathrm{ClA}$ and each individual was genotyped with markers spanning the congenic fragment. We observed that RIIIS/J alleles at marker D5Mit113 (78 Mbp) promoted disease incidence (Table 1). In contrast, one RIIIS/J allele at the marker D5Mit136, in the telomeric part of the fragment, protected against CIA development (Table 1). There was no difference in mean maximum score of the affected mice, except for females with RIIIS/J alleles at marker D5Mit136, which had significantly lower CIA scores compared with littermate controls (Table 1). This is in line with the male mice carrying heterozygous alleles at D5Mit136, where none of the mice developed arthritis.

In Table 2, correlation between the disease severity phenotype AUC, day 50 to 73 after immunisation, and genotype is shown. The AUC is the sum of scores for each individual mouse during a defined test period and describes the development of disease in terms of onset, duration and severity. In line with the disease incidence data (Table 1), RIIIS/J alleles at D5Mit113 promoted disease, whereas one RIIIS/J allele at about 120 Mbp (D5Mit136, D5Mit367) almost completely protected from CIA (Table 2). From these results we conclude that Eae39 harbors genes that, in addition to controlling EAE, are important for susceptibility to $\mathrm{CIA}$, and that the region contains 
Arthritis Research \& Therapy Vol 11 No 1 Lindvall et al.

Table 1

Incidence and mean maximum score of collagen-induced arthritis (CIA) in Eae39 congenic mice

\begin{tabular}{|c|c|c|c|c|c|c|c|}
\hline Phenotype & Marker & $M b p^{b}$ & Group & $\mathrm{a} / \mathrm{a}^{\mathrm{c}}$ & $a / b$ & $b / b$ & $p$-value ${ }^{d}$ \\
\hline \multirow[t]{6}{*}{ Incidence } & D5Mit113 & 77.68 & Total & $10 / 14(71 \%)$ & $7 / 12(58 \%)$ & $8 / 42(19 \%)$ & 0.0005 \\
\hline & & & Males & $3 / 5(60 \%)$ & $4 / 9(44 \%)$ & $2 / 21(10 \%)$ & 0.0222 \\
\hline & & & Females & $7 / 9(78 \%)$ & $3 / 3(100 \%)$ & $6 / 21(29 \%)$ & 0.0082 \\
\hline & D5Mit136 & 119.18 & Total & $11 / 15(73 \%)$ & $3 / 19$ (16\%) & $11 / 34(32 \%)$ & 0.0019 \\
\hline & & & Males & $3 / 5(60 \%)$ & $0 / 10(0 \%)$ & $6 / 20(30 \%)$ & 0.0345 \\
\hline & & & Females & $8 / 10(80 \%)$ & $3 / 9(33 \%)$ & $5 / 14(36 \%)$ & 0.0573 \\
\hline \multirow[t]{6}{*}{ Mean max score } & D5Mit113 & 77.68 & Total & $23 \pm 5$ & $21 \pm 5$ & $21 \pm 7$ & 0.7766 \\
\hline & & & Males & $31 \pm 15$ & $20 \pm 10$ & $14 \pm 2$ & 0.3280 \\
\hline & & & Females & $20 \pm 5$ & $22 \pm 10$ & $24 \pm 9$ & 0.9604 \\
\hline & D5Mit136 & 119.18 & Total & $21 \pm 5$ & $6 \pm 4$ & $27 \pm 15$ & 0.1034 \\
\hline & & & Males & $31 \pm 15$ & & $18 \pm 3$ & 0.1948 \\
\hline & & & Females & $18 \pm 5$ & $6 \pm 4$ & $37 \pm 6$ & 0.0317 \\
\hline
\end{tabular}

aShows the mean incidence and the mean maximum score of mice with the respective genotypes on markers D5Mit113 and D5Mit136.

Calculations were made on all mice in Figures 1 and 3 (a to I), and littermate controls. The sub-interval congenic mice were generated by intercrossing the $\mathrm{C} 1$ congenic mice (Figure 1).

bMbp = mega base pairs. The Mbp position is according to Ensembl release 49.

$\mathrm{c} a / \mathrm{a}=$ homozygous RIIIS/J alleles; $\mathrm{b} / \mathrm{b}=$ homozygous B10.RIII alleles; $\mathrm{a} / \mathrm{b}=$ heterozygous.

dStatistics for incidence was calculated with Chi squared test. Statistics for severity was calculated with Kruskal-Wallis test and Mann-Whitney U test.

eMean of the maximum score for all affected mice in Figures 1 and 3.

Table 2

CIA severity in Eae39 congenic mice

\section{$\operatorname{AUC}(\mathrm{d} 50-73)$ a}

\begin{tabular}{llllll} 
Marker & Mbp & $\mathrm{a} / \mathrm{a}^{\mathrm{c}}(\mathrm{n})$ & $\mathrm{a} / \mathrm{b}(\mathrm{n})$ & $\mathrm{b} / \mathrm{b}(\mathrm{n})$ & $\mathrm{p}$-value \\
\hline D5Mit113 & 77.68 & $126 \pm 41(14)$ & $87 \pm 35(12)$ & $30 \pm 15(42)$ & 0.0006 \\
D5Mit157 & 101.06 & $118 \pm 39(15)$ & $41 \pm 17(27)$ & $46 \pm 24(26)$ & 0.0071 \\
D5Mit240 & 109.52 & $118 \pm 39(15)$ & $33 \pm 16(27)$ & $55 \pm 25(26)$ & 0.0075 \\
D5Mit136 & 119.18 & $118 \pm 39(15)$ & $4 \pm 4(19)$ & $66 \pm 22(34)$ & 0.0023 \\
D5Mit367 & 120.31 & $111 \pm 37(16)$ & $5 \pm 4(17)$ & $66 \pm 22(34)$ & 0.0077 \\
D5Mit137 & 123.73 & $107 \pm 44(13)$ & $21 \pm 13(22)$ & $68 \pm 22(33)$ & 0.1014 \\
D5Mit95 & 125.31 & $99 \pm 41(14)$ & $22 \pm 14(21)$ & $68 \pm 22(33)$ & 0.1799 \\
D5Mit161 & 127.40 & $106 \pm 44(13)$ & $24 \pm 14(35)$ & $64 \pm 21(20)$ & 0.2488 \\
D5Mit59 & 128.20 & $99 \pm 41(14)$ & $25 \pm 15(19)$ & $66 \pm 22(34)$ & 0.2322 \\
D5Mit31 & 139.00 & $125 \pm 50(11)$ & $47 \pm 34(8)$ & $48 \pm 16(49)$ & 0.0423
\end{tabular}

aArea under curve (AUC) is the mean \pm standard error of the total sum of scores for mice with the respective genotypes (day 50 until day 73 ). All mice in Figures 1 and 3 (a to I), and littermate controls (b/b) are included in the calculations. The sub-interval congenic mice were generated by intercrossing the $\mathrm{C} 1$ congenic mice (Figures 1 and 2 ).

${ }^{b} \mathrm{Mbp}=$ mega base pairs. The Mbp position is according to Ensembl release 49.

$\mathrm{c} a / \mathrm{a}=$ homozygous RIIIS/J alleles; $\mathrm{b} / \mathrm{b}=$ homozygous B10.RIII alleles; $\mathrm{a} / \mathrm{b}=$ heterozygous.

dStatistics calculated with Kruskal-Wallis test. 


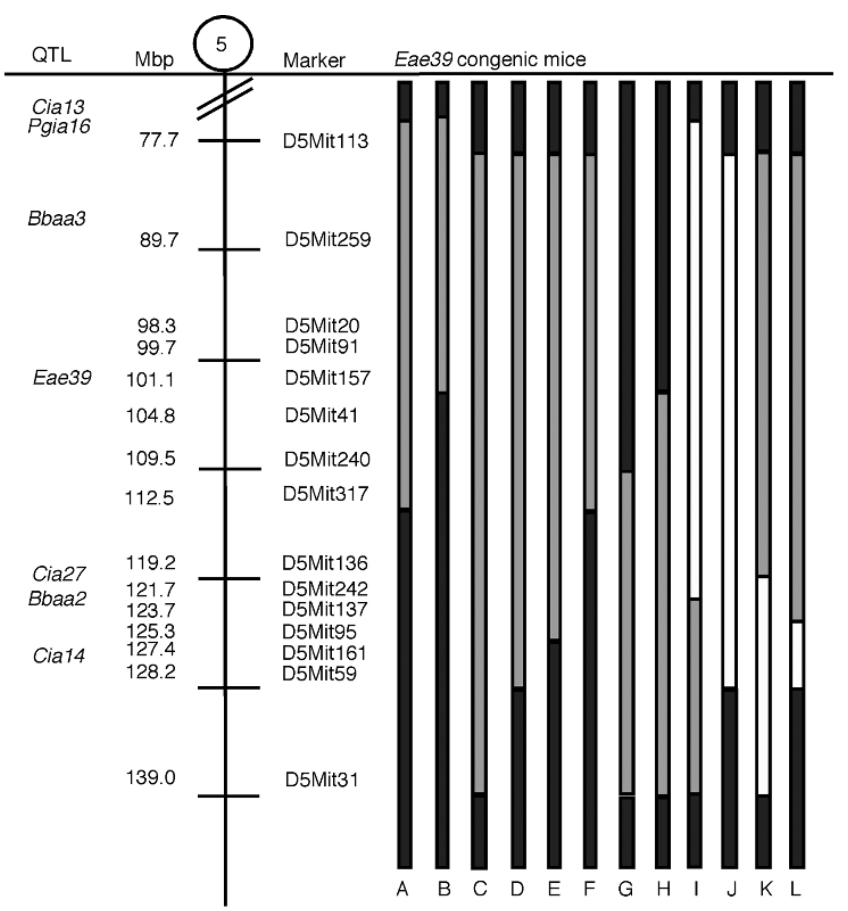

Eae39 sub-interval congenic mice. The sub-interval congenic mice were generated by intercrossing heterozygous $\mathrm{C} 1$ congenic mice. Black $=$ two B10.RIII alleles; white = two RIIIS/J alleles; grey = heterozygous. Mbp = mega base pairs (positions according to Ensembl release 49).

genes operating in different directions in the disease development.

In humans, women are more affected by RA than men. The sex influence on susceptibility to CIA is, however, normally the opposite in mice. In the first investigation of ClA development in mice with overlapping Eae39 sub-interval congenic fragments, we observed that female congenic mice had the same, or slightly higher, incidence of disease compared with male mice (Table 1). Severity of CIA (mean maximum score) was the same, except for females homozygous for B10.RIII alleles (b/ b) at marker D5Mit136, in which the severity was higher $(p<$ 0.05) compared with male mice (Table 1). From the original mapping experiment, Eae39 was linked to development of acute EAE in male mice [13]. For this reason, and in order to keep the number of mice used to a minimum, we decided to continue the present study with male mice only.

\section{The collagen type II antibody response is controlled by genes in the Eae39 locus}

In an F2 cross between the arthritis susceptible DBA/1J and the resistant $\mathrm{FVB} / \mathrm{N}$ strains, it was recently shown that the Cia27 locus controls anti-collagen type II IgG2a antibody levels [16]. To investigate the corresponding region within the Eae39 locus for disease phenotypes, we produced mice with smaller, overlapping congenic fragments (C2 to C5) (Figure 4) and studied the anti-collagen antibody response after immunisation. The IgG1, IgG2c, IgG3 and IgM anti-collagen serum levels at day 14 after immunisation were significantly lower in mice with the $\mathrm{C} 2$ congenic fragment (Figure 4) compared with littermate controls (Table 3 ). By comparing antibody levels in mice with the $\mathrm{C} 3$ and $\mathrm{C} 4$ congenic fragments, we found that the anti-collagen type II serum titres of the IgG2c isotype were significantly lower in mice with the $\mathrm{C} 4$ fragment compared with littermates and to mice with the C3 fragment. Mice with the C5 fragment (spanning from D5Mit317 (112 Mbp) to D5Mit367 (120 Mbp)) had significantly lower IgG1, IgG2c, IgG3 and total Ig serum levels compared with littermate controls (Table 3 ). This confirms the effect on the antibody response observed with the $\mathrm{C} 2$ fragment and shows that genes in this region control antibody responses to type II collagen.

\section{Collagen-induced arthritis development and antibody responses to type II collagen in the $\mathrm{C5}, \mathrm{C6}, \mathrm{C9}, \mathrm{C10}$, and C11 congenic mice}

Investigation of CIA development in C5 congenic mice showed that mice with one RIIISJ allele in this interval are protected from disease development compared with littermate controls (C5 congenics, incidence $=19 \%$, mean maximum score $=24 \pm 9$; littermate controls, incidence $=50 \%$, and mean maximum score $=31 \pm 3$; Table 4 and Figure $5 b$ ).

To further dissect the C5 region within the Eae39 locus, we bred congenic mice with overlapping fragments spanning the $\mathrm{C} 5$ region (C6, C9-C11) (Figure 5a). The new congenic mice were investigated for $\mathrm{CIA}$ and antibody responses to type II collagen. When splitting up the C5 fragment, we observed 
Figure 4

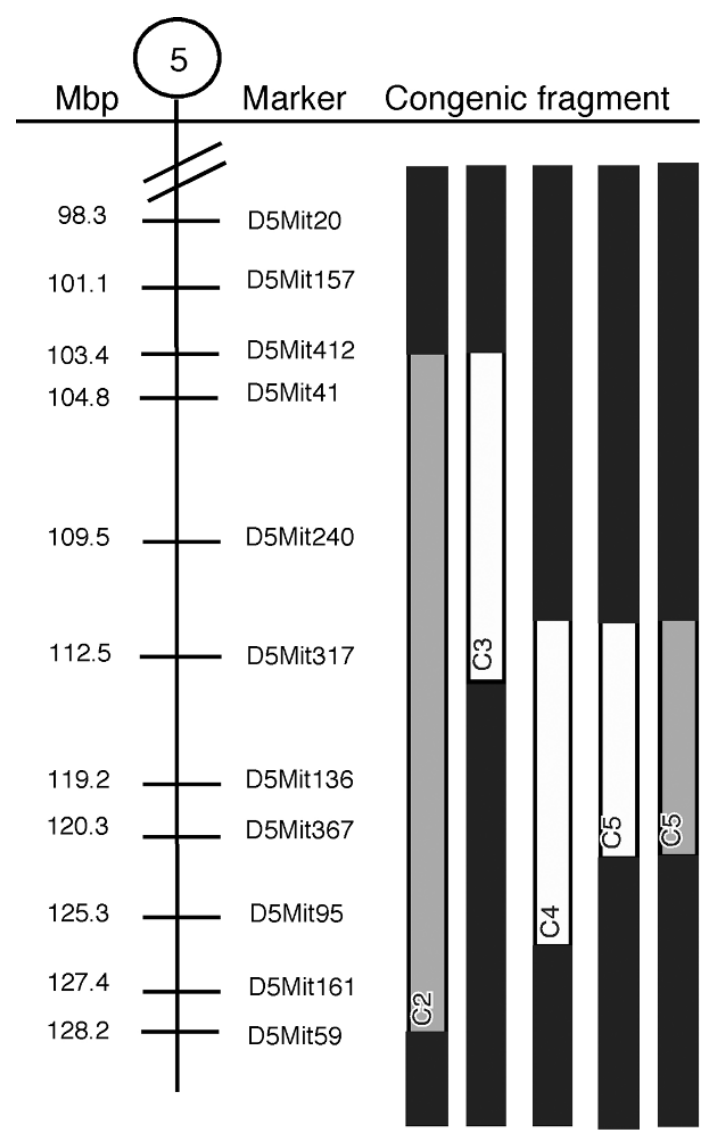

Schematic outline of congenic fragments in the Eae39 locus. C2 (D5Mit412 - D5Mit59); C3 (D5Mit412 - D5Mit317); C4 (D5Mit317 D5Mit95); C5 (D5Mit317 - D5Mit367). The C3 and C4 fragments were generated by backcrossing the $\mathrm{C} 2$ fragment to the parental B10.RIII strain and subsequently intercrossing the offspring. The C5 fragment was generated by backcrossing the $\mathrm{C} 4$ fragment to the parental B10.RIII strain and subsequently intercrossing the offspring. Black = two B10.RIII alleles; white = two RIIIS/J alleles; grey = heterozygous.

two different disease patterns. Mice with the C9 congenic fragment, which in contrast to C5 does not include the D5Mit317 marker, had a similar non-severe disease pattern to mice with the C5 fragment (Table 4, Figure 5d). Mice with the C6 fragment, covering the centromeric part but lacking the most telomeric part of the C5 fragment, developed more severe arthritis compared with mice with the C9 fragment (Table 4, Figures 5c,d). In mice with the $\mathrm{C} 10$ and $\mathrm{C} 11$ congenic fragments, a different pattern of disease development was observed because these mice were no longer protected from CIA, but instead developed more severe disease compared with littermate controls (Figures $5 e$ and $5 f$, Table 4).

The anti-collagen type II antibody titre was not significantly lower in mice with the C6 and C9 fragments compared with the controls (Table 5). In the $\mathrm{C} 10$ and $\mathrm{C} 11$ congenic mice, the collagen type II antibody levels followed the disease course and the antibody concentrations were significantly higher compared with the littermate controls (Table 5).

In conclusion, when splitting up the C5 fragment into smaller intervals, we suggest a disease-controlling gene (or genes) close to the D5Mit317 marker in the upper part of the fragment. This part of $\mathrm{C} 5$ is shared with the disease promoting congenic fragments $\mathrm{C} 10$ and $\mathrm{C} 11$. Although not statistically significant for mice with the $\mathrm{C} 6$ fragment, the results from the $\mathrm{C} 6$ and $\mathrm{C} 9$ congenic mice suggest that a gene conferring protection against CIA development when one RIIIS/J allele is present, is located close to the D5Mit136 marker. In contrast to the $\mathrm{C} 6$ fragment, the $\mathrm{C} 9$ does not include the promoting gene/genes around the D5Mit317 marker, which could explain why the C9 congenic mice are more protected from disease development. Another possibility would be that there is another protecting gene close to the D5Mit367 marker, which is not present in the $\mathrm{C} 6$ fragment.

\section{Discussion}

This study demonstrates that genes within the Eae39 on mouse chromosome 5 control development of $\mathrm{ClA}$, and that this locus contains sub-loci that balance out each other in susceptibility to disease. By subdividing the original locus into smaller congenic intervals, we observe stronger effects on the disease phenotype in either direction. The original locus was defined in EAE, but here we show that Eae39 additionally controls CIA. Several QTLs for disease development in arthritis models have been mapped to this region: CIA (Cia13, Cia14 and Cia27) $[15,16]$, proteoglycan-induced arthritis (Pgia16) [17] and Borrelia burgdorferi-associated arthritis (Bbaa3 and Bbaa2) [18]. The homologous regions in rats and humans have been linked to EAE development [20], pristane-induced arthritis [21], CIA [22] and RA [23,24], MS [25-27] and type 1 diabetes, respectively [28]. This suggests a shared genetic pathway in autoimmune diseases that is controlled by genes in this region.

The Eae39 locus was previously identified in a backcross between the B10.RIII and RIIIS/J mouse strains and was shown to control acute EAE in male mice. The inheritance pattern showed that one RIIIS/J allele conferred protection from EAE [13]. We, and others, have previously demonstrated that loci linked to the development of polygenic diseases can consist of several sub-QTLs, operating in an additive fashion or in different directions in the control of the disease trait $[9,10,29$ 32]. In the present study, we suggest that the original Eae39 locus harbors at least three genes that are involved in disease development (Figure 6). This could explain why the Eae39 locus was not found in previous EAE and CIA experiments with B10.RIII/RIIIS/J crosses, where the number of mice did not allow for the density of genetic recombinations needed to reveal a disease protecting or enhancing locus $[8,14]$. Mice with a small heterozygous Eae39 congenic fragment in the telomeric part of Eae39 were protected from disease. In con- 
Table 3

\begin{tabular}{|c|c|c|c|c|c|c|}
\hline Congenic fragment ${ }^{a}$ & Day after immunisation & Antibody isotype & $a / a^{b}$ & $a / b^{c}$ & $b / b^{d}$ & $p$-value \\
\hline \multirow[t]{4}{*}{$\mathrm{C} 2$} & 14 & $\lg \mathrm{l} 1$ & & $65^{f} \pm 7 g$ & $115 \pm 13$ & 0.0006 \\
\hline & & $\lg G 2 c$ & & $80 \pm 8$ & $114 \pm 12$ & 0.0172 \\
\hline & & $\lg G 3$ & & $97 \pm 12$ & $176 \pm 25$ & 0.0017 \\
\hline & & $\lg M$ & & $113 \pm 9$ & $171 \pm 15$ & 0.0003 \\
\hline \multirow[t]{4}{*}{ C3 } & 54 & $\lg 1_{1}$ & $187 \pm 30$ & & $381 \pm 118$ & 0.2667 \\
\hline & & $\lg G 2 c$ & $1468 \pm 405$ & & $987 \pm 373$ & 0.6634 \\
\hline & & $\operatorname{lgG} 3$ & $238 \pm 46$ & & $275 \pm 62$ & 0.2852 \\
\hline & & $\lg M$ & $102 \pm 15$ & & $155 \pm 57$ & 0.4862 \\
\hline \multirow[t]{4}{*}{$\mathrm{C} 4$} & 54 & $\lg G 1$ & $162 \pm 57$ & & $272 \pm 99$ & 0.3465 \\
\hline & & $\lg G 2 c$ & $350 \pm 73$ & & $797 \pm 162$ & 0.0280 \\
\hline & & $\operatorname{lgG} 3$ & $176 \pm 52$ & & $214 \pm 86$ & 0.4118 \\
\hline & & $\lg M$ & $81 \pm 9$ & & $89 \pm 17$ & $>0.999$ \\
\hline \multirow[t]{4}{*}{ C5 } & 14 & $\lg G 1$ & $139 \pm 20$ & $258 \pm 37$ & $335 \pm 63$ & 0.0172 \\
\hline & & $\lg G 2 c$ & $240 \pm 71$ & $368 \pm 73$ & $1201 \pm 409$ & 0.0076 \\
\hline & & $\lg G 3$ & $89 \pm 18$ & $142 \pm 19$ & $189 \pm 24$ & 0.0132 \\
\hline & & $\lg M$ & $306 \pm 68$ & $633 \pm 98$ & $875 \pm 142$ & 0.0041 \\
\hline
\end{tabular}

aCongenic fragments according to Figure 4.

bMale mice with homozygous RlllS/J alleles in C3 $(n=22)$, C4 $(n=12)$ and C5 $(n=10)$.

cMale mice with heterozygous alleles in C2 $(n=45)$ and C5 $(n=10)$.

dMale mice with homozygous B10.RIII alleles in C2 $(n=28)$, C3 $(n=9)$, C4 $(n=8)$ and C5 $(n=7)$.

eStatistics was calculated with Mann-Whitney $U$ test and Kruskal-Wallis test.

fArbitrary antibody concentration. Anti-collagen type II antibodies in non-immunised mice are not detectable.

gMean \pm standard error of the mean.

trast, homozygous RIIIS/J alleles in the complete Eae39 region or one RIIIS/J allele at the D5Mit113 (77.7 Mbp) marker, in the centromeric part of the fragment, promoted disease. This supports a complex inheritance pattern where RIIIS/J alleles in the centromeric part of Eae39 promote disease, whereas one RIIIS/J allele in the telomeric part of Eae39 protects against disease. The data could be explained by a strong dominant disease-promoting RIIIS/J gene close to D5Mit113, which overcomes the effect of the protecting RIIIS/J alleles in the telomeric part of the fragment. We have previously reported a similar inheritance effect between two OTLs, Cia26 and Cia30, within the Eae2 locus on mouse chromosome 15 [10].

Splitting up the disease protecting C5 fragment (Figure 5) into smaller congenic intervals, revealed opposing effects on CIA development. RIIIS/J alleles in the upper part of C5 (110.1 to 114.6 Mbp) strongly enhanced the disease, whereas mice carrying congenic fragments including the D5Mit136 marker (119.8 Mbp) were protected from disease development. The observation that the $\mathrm{C} 5$ fragment, sharing the disease-promoting parts with the $\mathrm{C} 10$ and $\mathrm{C} 11$ fragments, is protective, could be explained by a gene close to D5Mit136 that has a stronger effect on disease compared with the disease promoting gene located close to D5Mit317. The length of the protective region is $3.2 \mathrm{Mbp}$ ( 117.7 to $121.0 \mathrm{Mbp}$ ). Except for the nitric oxide synthase 1 (Nos1), this interval contains no genes known to be directly involved in inflammation, but includes genes important in cell signalling, regulation (Taok3, Wsb2, Rfc5, Ksr2, Tesc) and development ( $T b \times 3, T b \times 5, L h \times 5)$.

In addition to studies of CIA development in the Eae39 congenic mice, we investigated the antibody response to type II collagen after immunisation. We observed that the C5 congenic mice had lower antibody responses to collagen type II and were protected from disease development. In contrast, mice carrying the disease promoting $\mathrm{C} 10$ and $\mathrm{C} 11$ congenic fragments had enhanced anti-collagen antibody titres. This may suggest that the same gene(s) influence anti-collagen 
(a)

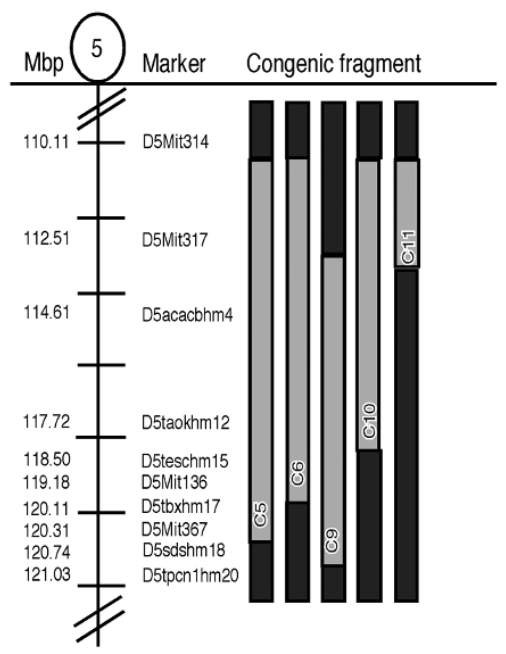

(c)

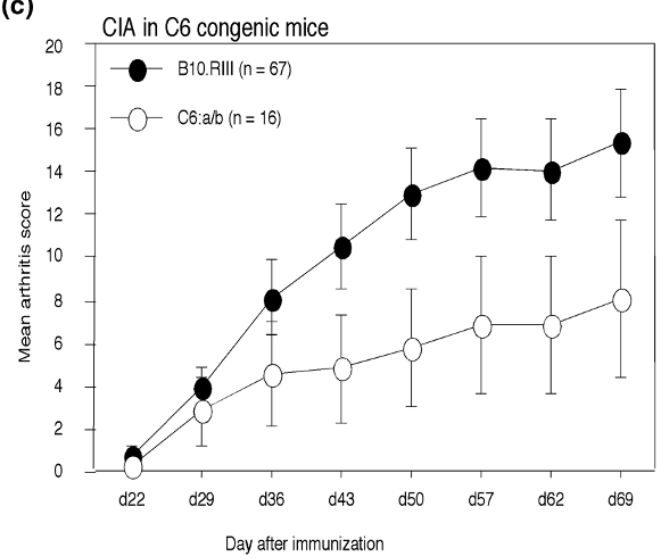

(e)

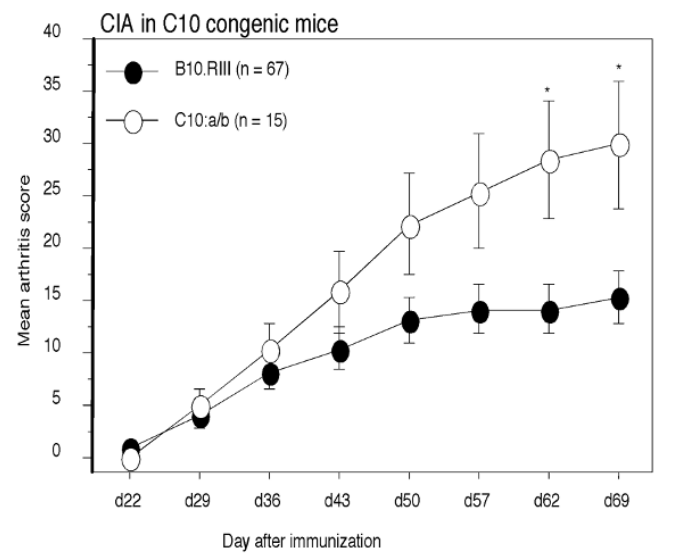

(b)

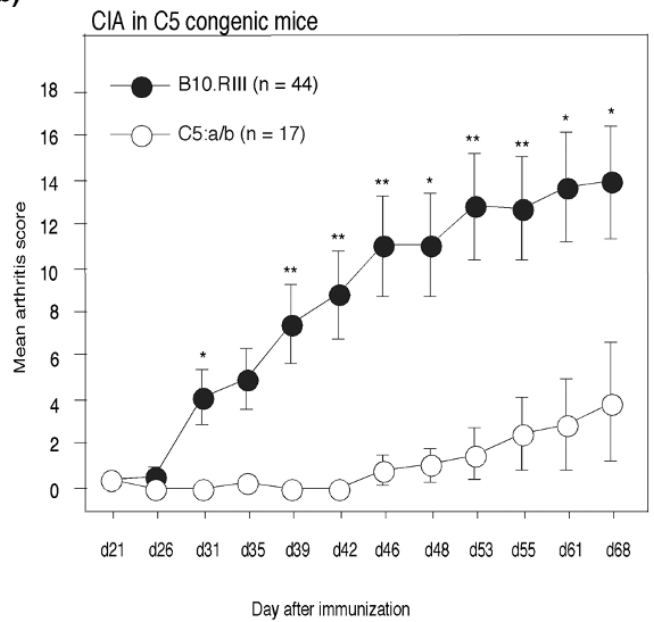

(d)

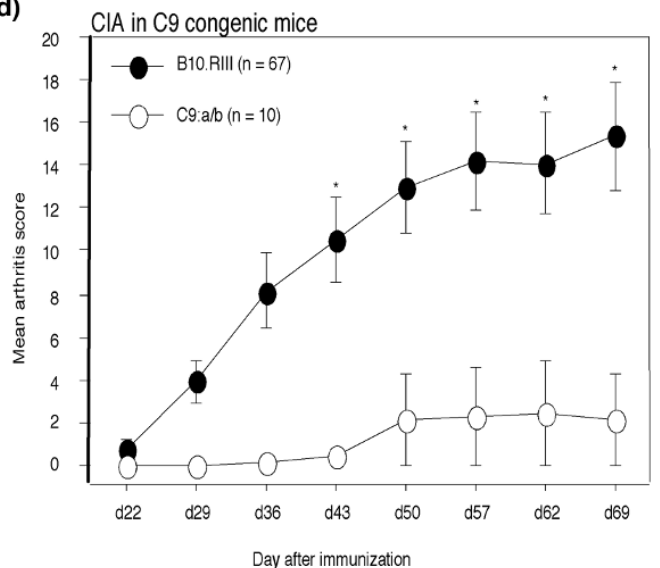

(f)

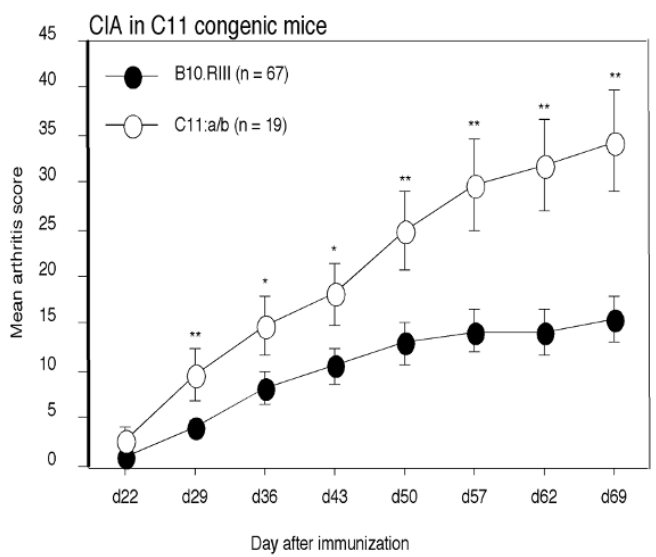

Collagen-induced arthritis (CIA) in Eae39 congenic mice. (a) A schematic outline of overlapping congenic fragments confined to the C5 interval. Black = two B10.RIII alleles; grey = heterozygous. (b - f) CIA development in C5, C6, C9, C10 and C11 congenic mice, and littermate controls. The littermate control group comprises all mice homozygous for B10.RIII alleles (b/b) from the breeding of the congenic mice. The different littermate control groups' data were pooled because they had similar disease progression. The C5 and C9 congenic fragment have been generated from $\mathrm{C} 4$ (Figure 4) by backcrossing to the B10.RIII parental strain and subsequently intercrossing the offspring. The C6, C10 and C11 were generated by backcrossing C5 congenic mice to the B10.RIII parental strain followed by intercrossing of the offspring. Stars indicate significant differences in mean arthritis score: ${ }^{*} p<$ $0.05,{ }^{\star \star} p<0.01$. 
Table 4

CIA phenotypes in $\mathrm{C5}, \mathrm{C6}, \mathrm{C}, \mathrm{C} 10$, and $\mathrm{C} 11$ congenic mice

\begin{tabular}{|c|c|c|c|c|c|c|c|}
\hline Phenotype ${ }^{a}$ & B10.RIIIb & C5 & B10.RIIIc & $\mathrm{C} 6$ & $\mathrm{Cg}$ & $\mathrm{C} 10$ & C11 \\
\hline Incidence & $22 / 44(50 \%)$ & $3 / 17(19 \%)^{*}$ & $32 / 67$ (48\%) & $6 / 16(38 \%)$ & $1 / 10(10 \%)^{\star}$ & $10 / 15(67 \%)$ & $14 / 19(74 \%)^{\star}$ \\
\hline Onset $^{d}$ & $37 \pm 2^{\mathrm{e}}$ & $49 \pm 3$ & $34 \pm 2$ & $34 \pm 4$ & 36 & $32 \pm 1.5$ & $29 \pm 1$ \\
\hline Severity ${ }^{f}$ & $31 \pm 3$ & $24 \pm 9$ & $35 \pm 3$ & $24 \pm 6$ & 24 & $46 \pm 3$ & $48 \pm 3^{*}$ \\
\hline AUCg & $101 \pm 20$ & $13 \pm 8^{*}$ & $80 \pm 13$ & $40 \pm 19$ & $10 \pm 10^{*}$ & $137 \pm 28$ & $166 \pm 27^{\star \star}$ \\
\hline
\end{tabular}

a Values for incidence, onset, mean maximum score and area under the curve (AUC) are the mean phenotype values for the respective congenic mice. The congenic intervals are outlined in Figure 5 a. Statistics was calculated with Chi squared test for incidence and Mann-Whitney $U$ test for onset, severity and AUC. * $p<0.05,{ }^{* \star} p<0.01$

bB10.RIII = littermate controls for mice with the C5 congenic (a/b) fragment.

CB10.RIII = littermate controls for mice with the C6, C9, C10 and C11 congenic (a/b) fragment.

dThe day for onset of disease.

eMean \pm standard error of the mean

fSeverity is the mean of the maximum score of all affected mice in the respective group.

gAUC is the mean of the total sum of scores for mice in the respective group (day 21 to 69 ).

Table 5

Anti-collagen type II antibody responses in C6, C9, C10 and $\mathrm{C} 11$ congenic mice

$\begin{array}{llllll}\text { Antibody isotype } & \text { B10.RIIIa } & \text { C6 } & \text { C9 } & \text { C10 } & \text { C11 }\end{array}$

\begin{tabular}{|c|c|c|c|c|c|}
\hline $\lg G 1$ & $2046^{b} \pm 276^{c}$ & $1567 \pm 265$ & $1354 \pm 193$ & $2520 \pm 388^{\star}$ & $2868 \pm 576^{\star}$ \\
\hline $\lg G 2 c$ & $2337 \pm 262$ & $1754 \pm 212$ & $2031 \pm 420$ & $2859 \pm 477$ & $4096 \pm 692^{\star *}$ \\
\hline $\lg G 3$ & $1873 \pm 141$ & $1364 \pm 273$ & $2144 \pm 473$ & $2483 \pm 370$ & $3021 \pm 409^{* *}$ \\
\hline $\lg$ Tot & $2705 \pm 300$ & $2038 \pm 291$ & $2439 \pm 661$ & $4130 \pm 551^{\star \star}$ & $3696 \pm 543^{* *}$ \\
\hline
\end{tabular}

aB10.RIII = littermate controls $(n=64)$ for mice with the different congenic fragments. The congenic intervals are outlined in Figure 5 a. C6 $(n=$ 14), C9 $(n=9), C 10(n=15), C 11(n=17)$.

bArbitrary antibody concentration in serum. Blood was collected day 21 after immunisation. Anti-collagen type II antibodies in non-immunized mice are not detectable.

cMean \pm standard error of the mean

Statistics was calculated with Mann-Whitney $U$ test, ${ }^{\star} p<0.05,{ }^{\star *} p<0.01$ 
Figure 6

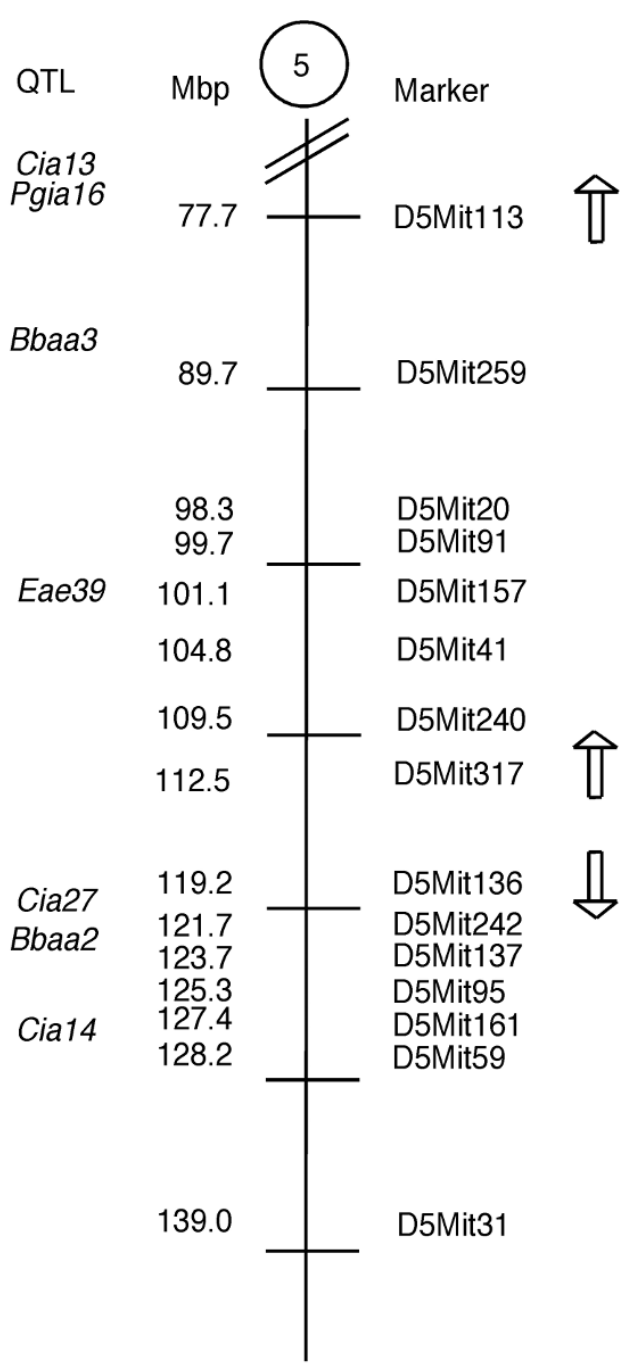

Collagen-induced arthritis (CIA) promoting- and protecting sub-loci within Eae39. The arrows indicate whether RIIIS/J alleles in this region enhanced or suppressed disease.

antibody titres together with the disease phenotype. Interestingly, Yu and colleagues [33] recently reported that the Cia27 locus on mouse chromosome 5 controls anti-collagen IgG2a antibody titres and the CIA disease phenotype. Although Cia27 was defined in an arthritis model with a different disease-inducing protocol and with mouse strains different from the strains used in the present study, it could be speculated that the same gene is operating in the two different models. Cia27 has been confined to $4.1 \mathrm{Mbp}$, and the peak marker is located at $120 \mathrm{Mbp}$, which corresponds to the genetic region found to control CIA disease phenotypes and anti-collagen type II antibody responses.

Male mice are normally more susceptible to CIA compared with female mice. In the present study, Eae39 sub-interval congenic female mice had as high an incidence of disease as male mice. Gender differences in susceptibility to CIA are believed to be dependent on hormones, genetic factors and behaviour [34]. We recently reported the identification of OTLs linked to CIA susceptibility in multiparous female mice [35], but this study did not reveal any linkage to mouse chromosome 5 . Interestingly, the Eae39 locus includes two genes that are involved in the effects of oestrogen signalling; the $G$ proteincoupled oestrogen receptor 1 (Gper, $139.9 \mathrm{Mbp}$ ) and oestrogen sulfotransferase (Sult1e1, $88.0 \mathrm{Mbp}$ ). The studies of smaller congenic fragments within Eae39 were performed with male mice and the gender susceptibility was not studied further. Investigations addressing any role for polymorphisms between B10.RIII and RIIIS/J in those genes would possibly contribute to the understanding of gender discrepancies in susceptibility to CIA.

This study demonstrates that breeding of mice with sub-congenic intervals, containing a limited number of genes, is informative in the dissection of OTLs defined in two-generationcrosses. Furthermore, it demonstrates that genes within the same disease pathways are located a close distance apart in the genome and possibly inherited together. Disease-protective polymorphisms have balancing effects, while a polymorphism in a different genetic context could increase the risk for disease.

\section{Conclusion}

We have located a region in the telomeric part of Eae39 on mouse chromosome 5 that contains genes that control incidence and severity of $\mathrm{CIA}$ and serum levels of anti-collagen type II antibodies. In addition, we suggest that this region is influenced by a locus close to the marker D5Mit113 (77.7 Mbp), where B10.RIII alleles together with one RIIIS/J allele at marker D5Mit136 (119.2 Mbp) result in protection from disease. The disease-protecting region in the telomeric part of Eae39 is $3.2 \mathrm{Mbp}$ and includes about 20 genes. Further studies will focus on the role of the genes within this sub-locus in the control of inflammatory disease- and sub-phenotypes.

\section{Competing interests}

The authors declare that they have no competing interests.

\section{Authors' contributions}

TL was responsible for the breeding of congenic mice, carried out the CIA and sub-phenotyping experiments, participated in the design of the study and drafted the manuscript. JK participated in the initial breeding of the congenic mice. $\mathrm{RH}$ participated in the design of the study and helped to draft the manuscript. ÅA participated in the design and coordination of the study, and helped to draft the manuscript.

\section{Acknowledgements}

We thank I. Bohlin for help with animal care. This work was supported by grants from the King Gustaf V 80-years Foundation, The Swedish Rheumatism Foundation, The Crafoord Foundation, The Danish Rheumatism Foundation, The Novo Nordisk Foundation, Greta and Johan 
Kocks Foundation, Österlunds Foundation ( $\mathrm{A} A)$, and from the European Union Grants Autocure (LSHB-2006-018661) and Neuropromise (LSHM-LT-018637) (RH).

\section{References}

1. Marrack P, Kappler J, Kotzin BL: Autoimmune disease: why and where it occurs. Nat Med 2001, 7:899-905.

2. Begovich AB, Carlton VE, Honigberg LA, Schrodi SJ, Chokkalingam AP, Alexander HC, Ardlie KG, Huang Q, Smith AM, Spoerke JM, Conn MT, Chang M, Chang SY, Saiki RK, Catanese JJ, Leong DU, Garcia VE, McAllister LB, Jeffery DA, Lee AT, Batliwalla F, Remmers E, Criswell LA, Seldin MF, Kastner DL, Amos Cl, Sninsky JJ, Gregersen PK: A missense single-nucleotide polymorphism in a gene encoding a protein tyrosine phosphatase (PTPN22) is associated with rheumatoid arthritis. Am J Hum Genet 2004, 75:330-337.

3. Suzuki A, Yamada R, Chang X, Tokuhiro S, Sawada T, Suzuki M, Nagasaki M, Nakayama-Hamada M, Kawaida R, Ono M, Ohtsuki M, Furukawa H, Yoshino S, Yukioka M, Tohma S, Matsubara T, Wakitani S, Teshima R, Nishioka Y, Sekine A, lida A, Takahashi A, Tsunoda T, Nakamura $Y$, Yamamoto K: Functional haplotypes of PADI4, encoding citrullinating enzyme peptidylarginine deiminase 4 , are associated with rheumatoid arthritis. Nat Genet 2003, 34:395-402.

4. Tokuhiro S, Yamada R, Chang X, Suzuki A, Kochi Y, Sawada T, Suzuki $M$, Nagasaki $M$, Ohtsuki $M$, Ono $M$, Furukawa $H$, Nagashima M, Yoshino S, Mabuchi A, Sekine A, Saito S, Takahashi A, Tsunoda T, Nakamura Y, Yamamoto K: An intronic SNP in a RUNX1 binding site of SLC22A4, encoding an organic cation transporter, is associated with rheumatoid arthritis. Nat Genet 2003, 35:341-348.

5. Gregory SG, Schmidt S, Seth P, Oksenberg JR, Hart J, Prokop A, Caillier SJ, Ban M, Goris A, Barcellos LF, Lincoln R, McCauley JL, Sawcer SJ, Compston DA, Dubois B, Hauser SL, Garcia-Blanco MA, Pericak-Vance MA, Haines JL, Multiple Sclerosis Genetics Group: Interleukin 7 receptor alpha chain (IL7R) shows allelic and functional association with multiple sclerosis. Nat Genet 2007, 39:1083-1091.

6. Lundmark F, Duvefelt K, lacobaeus E, Kockum I, Wallström E, Khademi M, Oturai A, Ryder LP, Saarela J, Harbo HF, Celius EG, Salter $\mathrm{H}$, Olsson T, Hillert J: Variation in interleukin 7 receptor alpha chain (IL7R) influences risk of multiple sclerosis. Nat Genet 2007, 39:1108-1113.

7. Trentham DE, Townes AS, Kang AH: Autoimmunity to type II collagen an experimental model of arthritis. J Exp Med 1977, 146:857-868.

8. Jirholt J, Cook A, Emahazion T, Sundvall M, Jansson L, Nordquist $\mathrm{N}$, Pettersson U, Holmdahl R: Genetic linkage analysis of collagen-induced arthritis in the mouse. Eur J Immunol 1998, 28:3321-3328.

9. Johannesson $M$, Karlsson J, Wernhoff $P$, Nandakumar $K S$, Lindqvist AK, Olsson L, Cook AD, Andersson A, Holmdahl R: Identification of epistasis through a partial advanced intercross reveals three arthritis loci within the Cia5 QTL in mice. Genes Immun 2005, 6:175-185.

10. Karlsson J, Johannesson M, Lindvall T, Wernhoff $P$, Holmdahl R, Andersson A: Genetic interactions in Eae2 control collageninduced arthritis and the CD4+/CD8+ T cell ratio. J Immunol 2005, 174:533-541.

11. Jansson L, Olsson T, Hojeberg B, Holmdahl R: Chronic experimental autoimmune encephalomyelitis induced by the 89-101 myelin basic protein peptide in B10RIII $(\mathrm{H}-2 \mathrm{r})$ mice. Eur $\mathrm{J}$ Immunol 1991, 21:693-699.

12. Jirholt J, Lindqvist $A B$, Holmdahl R: The genetics of rheumatoid arthritis and the need for animal models to find and understand the underlying genes. Arthritis Res 2001, 3:87-97.

13. Karlsson J, Zhao X, Lonskaya I, Neptin M, Holmdahl R, Andersson A: Novel quantitative trait loci controlling development of experimental autoimmune encephalomyelitis and proportion of lymphocyte subpopulations. J Immunol 2003, 170:1019-1026.

14. Sundvall M, Jirholt J, Yang HT, Jansson L, Engstrom A, Pettersson $\mathrm{U}$, Holmdahl R: Identification of murine loci associated with susceptibility to chronic experimental autoimmune encephalomyelitis. Nat Genet 1995, 10:313-317.
15. Adarichev VA, Valdez JC, Bardos T, Finnegan A, Mikecz K, Glant TT: Combined autoimmune models of arthritis reveal shared and independent qualitative (binary) and quantitative trait loci. $\mathrm{J}$ Immunol 2003, 170:2283-2292.

16. Bauer K, Yu X, Wernhoff $P$, Koczan D, Thiesen HJ, Ibrahim SM: Identification of new quantitative trait loci in mice with collagen-induced arthritis. Arthritis Rheum 2004, 50:3721-3728.

17. Otto JM, Chandrasekeran R, Vermes C, Mikecz K, Finnegan A, Rickert SE, Enders JT, Glant TT: A genome scan using a novel genetic cross identifies new susceptibility loci and traits in a mouse model of rheumatoid arthritis. J Immunol 2000, 165:5278-5286.

18. Weis JJ, McCracken BA, Ma Y, Fairbairn D, Roper RJ, Morrison TB, Weis JH, Zachary JF, Doerge RW, Teuscher C: Identification of quantitative trait loci governing arthritis severity and humoral responses in the murine model of Lyme disease. J Immunol 1999, 162:948-956.

19. Carlsen S, Hansson AS, Olsson H, Heinegard D, Holmdahl R: Cartilage oligomeric matrix protein (COMP)-induced arthritis in rats. Clin Exp Immunol 1998, 114:477-484.

20. Bergsteinsdottir K, Yang HT, Pettersson U, Holmdahl R: Evidence for common autoimmune disease genes controlling onset, severity, and chronicity based on experimental models for multiple sclerosis and rheumatoid arthritis. J Immunol 2000, 164:1564-1568.

21. Vingsbo-Lundberg $C$, Nordquist $N$, Olofsson $P$, Sundvall M, Saxne $\mathrm{T}$, Pettersson U, Holmdahl R: Genetic control of arthritis onset, severity and chronicity in a model for rheumatoid arthritis in rats. Nat Genet 1998, 20:401-404.

22. Griffiths MM, Wang J, Joe B, Dracheva S, Kawahito Y, Shepard JS, Reese VR, McCall-Vining S, Hashiramoto A, Cannon GW, Remmers EF, Wilder RL: Identification of four new quantitative trait loci regulating arthritis severity and one new quantitative trait locus regulating autoantibody production in rats with collagen-induced arthritis. Arthritis Rheum 2000, 43:1278-1289.

23. Jawaheer D, Seldin MF, Amos Cl, Chen WV, Shigeta R, Monteiro J, Kern M, Criswell LA, Albani S, Nelson JL, Clegg DO, Pope R, Schroeder HW Jr, Bridges SL Jr, Pisetsky DS, Ward R, Kastner DL, Wilder RL, Pincus T, Callahan LF, Flemming D, Wener MH, Gregersen PK: A genomewide screen in multiplex rheumatoid arthritis families suggests genetic overlap with other autoimmune diseases. Am J Hum Genet 2001, 68:927-936.

24. MacKay K, Eyre S, Myerscough A, Milicic A, Barton A, Laval S, Barrett J, Lee D, White S, John S, Brown MA, Bell J, Silman A, Ollier W, Wordsworth $\mathrm{P}$, Worthington J: Whole-genome linkage analysis of rheumatoid arthritis susceptibility loci in 252 affected sibling pairs in the United Kingdom. Arthritis Rheum 2002, 46:632-639.

25. Vitale E, Cook S, Sun R, Specchia C, Subramanian K, Rocchi M, Nathanson D, Schwalb M, Devoto M, Rohowsky-Kochan C: Linkage analysis conditional on HLA status in a large North American pedigree supports the presence of a multiple sclerosis susceptibility locus on chromosome 12p12. Hum Mol Genet 2002, 11:295-300.

26. Xu C, Dai Y, Fredrikson S, Hillert J: Association and linkage analysis of candidate chromosomal regions in multiple sclerosis: indication of disease genes in 12q23 and 7ptr-15. Eur J Hum Genet 1999, 7:110-116.

27. Xu C, Dai Y, Lorentzen JC, Dahlman I, Olsson T, Hillert J: Linkage analysis in multiple sclerosis of chromosomal regions syntenic to experimental autoimmune disease loci. Eur J Hum Genet 2001, 9:458-463.

28. McAleer MA, Reifsnyder P, Palmer SM, Prochazka M, Love JM, Copeman JB, Powell EE, Rodrigues NR, Prins J-B, Serreze DV, DeLarato NH, Wicker LS, Peterson LB, Schork NJ, Todd JA, Leiter $\mathrm{EH}$ : Crosses of NOD mice with the related NON strain. A polygenic model for IDDM. Diabetes 1995, 44:1186-1195.

29. Ahlqvist $\mathrm{E}$, Bockermann R, Holmdahl R: Fragmentation of two quantitative trait loci controlling collagen-induced arthritis reveals a new set of interacting subloci. J Immunol 2007, 178:3084-3090.

30. Hill NJ, Lyons PA, Armitage N, Todd JA, Wicker LS, Peterson LB: NOD Idd5 locus controls insulitis and diabetes and overlaps the orthologous CTLA4/IDDM12 and NRAMP1 loci in humans. Diabetes 2000, 49:1744-1747.

31. Morel L, Blenman KR, Croker BP, Wakeland EK: The major murine systemic lupus erythematosus susceptibility locus, 
Sle1, is a cluster of functionally related genes. Proc Natl Acad Sci USA 2001, 98:1787-1792.

32. Otto JM, Cs-Szabo G, Gallagher J, Velins S, Mikecz K, Buzas El, Enders JT, Li Y, Olsen BR, Glant TT: Identification of multiple loci linked to inflammation and autoantibody production by a genome scan of a murine model of rheumatoid arthritis. Arthritis Rheum 1999, 42:2524-2531.

33. Yu X, Bauer K, Wernhoff P, Koczan D, Moller S, Thiesen HJ, Ibrahim SM: Fine mapping of collagen-induced arthritis quantitative trait Loci in an advanced intercross line. J Immuno/ 2006, 177:7042-7049.

34. Brand DD, Kang AH, Rosloniec EF: The mouse model of collagen-induced arthritis. Methods Mol Med 2004, 102:295-312.

35. Liljander M, Sällström MA, Andersson S, Andersson Á, Holmdahl $\mathrm{R}$, Mattsson R: Identification of collagen-induced arthritis loci in aged multiparous female mice. Arthritis Res Ther 2006, 8:R45. 